\title{
Demonstration of the On-the-Fly Shielding Analysis Method
}

\section{Spent Fuel and Waste Disposition}

\author{
Prepared for \\ US Department of Energy \\ Office of Nuclear Energy \\ Integrated Waste Management \\ Georgeta Radulescu, \\ Kaushik Banerjee, and L. Paul Miller
}

Oak Ridge National Laboratory

March 26, 2021 M3SF-21OR020401016 ORNL/SPR-2021/1913 


\section{DISCLAIMER}

This information was prepared as an account of work sponsored by an agency of the U.S. Government. Neither the U.S. Government nor any agency thereof, nor any of their employees, makes any warranty, expressed or implied, or assumes any legal liability or responsibility for the accuracy, completeness, or usefulness, of any information, apparatus, product, or process disclosed, or represents that its use would not infringe privately owned rights. References herein to any specific commercial product, process, or service by trade name, trade mark, manufacturer, or otherwise, does not necessarily constitute or imply its endorsement, recommendation, or favoring by the U.S. Government or any agency thereof. The views and opinions of authors expressed herein do not necessarily state or reflect those of the U.S. Government or any agency thereof.

This is a technical report that does not take into account contractual limitations or obligations under the Standard Contract for Disposal of Spent Nuclear Fuel and/or High-Level Radioactive Waste (Standard Contract) (10 CFR Part 961). For example, under the provisions of the Standard Contract, spent nuclear fuel in multi-assembly canisters is not an acceptable waste form, absent a mutually agreed to contract amendment.

To the extent discussions or recommendations in this report conflict with the provisions of the Standard Contract, the Standard Contract governs the obligations of the parties, and this report in no manner supersedes, overrides, or amends the Standard Contract.

This report reflects technical work which could support future decision making by DOE. No inferences should be drawn from this report regarding future actions by DOE, which are limited both by the terms of the Standard Contract and Congressional appropriations for the Department to fulfill its obligations under the Nuclear Waste Policy Act including licensing and construction of a spent nuclear fuel repository. 


\section{SUMMARY}

This report documents work performed supporting the US Department of Energy (DOE) Office of Nuclear Energy (NE) Spent Fuel and Waste Disposition (SFWD) Integrated Waste Management activities under work breakdown structure element 1.08.02.04.01, "Data and Tools Development, Validation, and Maintenance." In particular, this report fulfills milestone M3SF-21OR020401016, "Implement on-the-fly dose analysis methodology in UNF-ST\&DARDS" within work package SF-21OR02040101, "Commercial SNF Characterization-ORNL."

The Used Nuclear Fuel—Storage, Transportation \& Disposal Analysis Resource and Data System (UNFST\&DARDS) enables automated dose rate calculations for spent nuclear fuel (SNF) transportation packages and storage casks using a Monte Carlo radiation transport code. The explicit method uses a detailed model of the SNF system and its contents. Therefore, a dose rate calculation is required for each as-loaded transportation package or storage cask because the SNF assemblies within a canister typically have unique irradiation characteristics. An alternate method, referred to as the "on-the-fly" shielding analysis method, has been proposed that requires only a set of Monte Carlo dose rate calculations for each transportation packaging/storage cask design. The results of the Monte Carlo dose rate calculations are independent of the SNF assembly irradiation and decay characteristics. The dose rate values may then be combined with the radiation source strength of the SNF assemblies associated with a particular transportation packaging/storage cask design to determine actual dose rates.

This report presents on-the-fly dose rate calculations for a representative SNF storage cask and verification of the on-the-fly dose rate calculation results by comparison with reference dose rate calculations using the explicit Monte Carlo dose rate calculation. The on-the-fly shielding analysis method was implemented in UNF-ST\&DARDS. A Python program was developed to process the MAVRIC dose rate results obtained by source particle type, energy group, and fuel geometry region. A Python processor created binary files, which were saved as a special UNF-ST\&DARDS library for onthe-fly shielding analyses. UNF-ST\&DARDS uses the precalculated on-the-fly binary libraries generated by the Python data processor and directly executes the Python code for on-the-fly dose analysis. This Python code unzips the pre-generated binary files mentioned above, reads the data, and combines them with user-specified sources for dose and uncertainty calculations. The Python programs were verified using Excel calculations and by comparison with the values obtained with the MAVRIC post-processing utilities applied to the $3 \mathrm{dmap}$ files. This method can currently be used to determine dose rates for asloaded HI-STORM FW storage casks. The UNF-ST\&DARDS analysis wizard for on-the-fly shielding analysis is described in this report. 
This page is intentionally left blank. 


\section{CONTENTS}

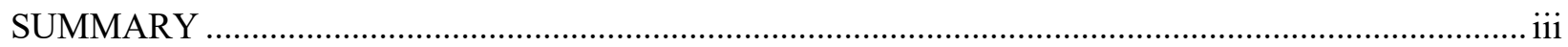

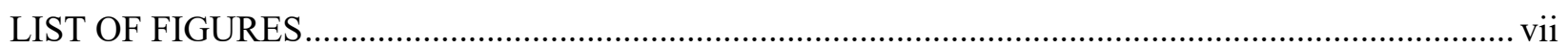

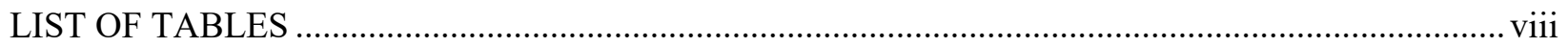

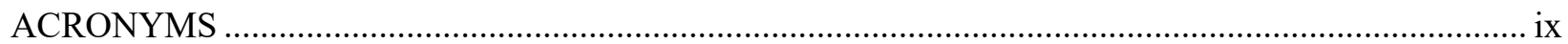

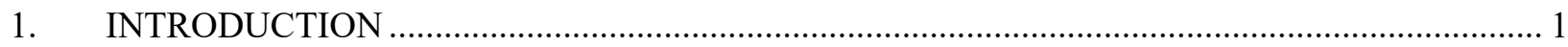

2. ANALYSIS METHODS, MODELS, AND COMPUTATIONAL TOOLS ................................ 3

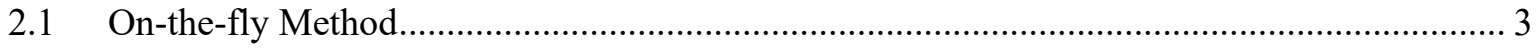

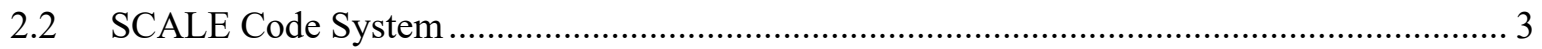

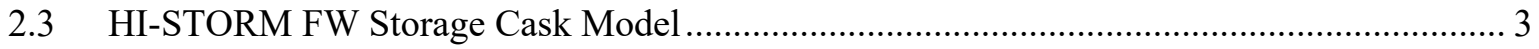

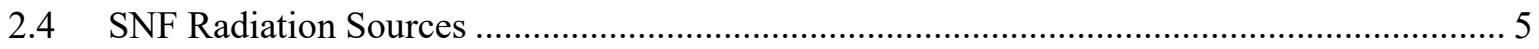

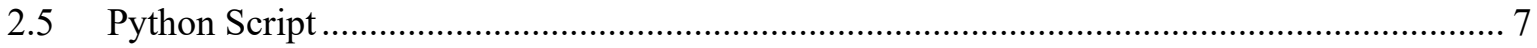

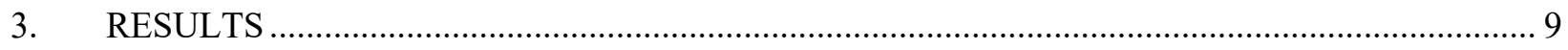

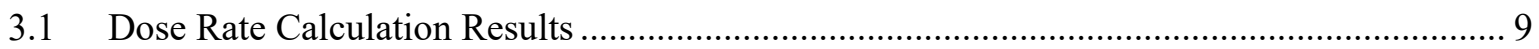

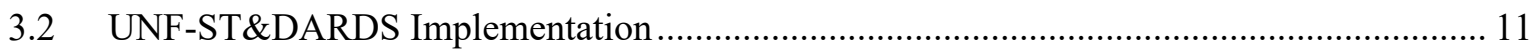

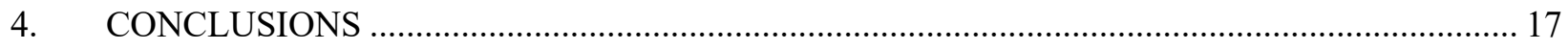

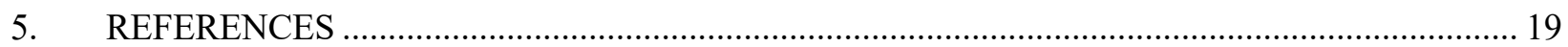


This page is intentionally left blank. 


\section{LIST OF FIGURES}

Figure 1. Vertical (a) and horizontal (b) cross-sectional views of the HI-STORM FW geometry model. .. .4

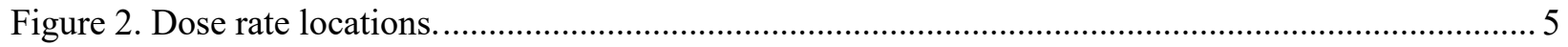

Figure 3: Directory structure used for MAVRIC data processing. ......................................................... 8

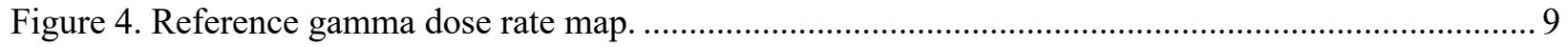

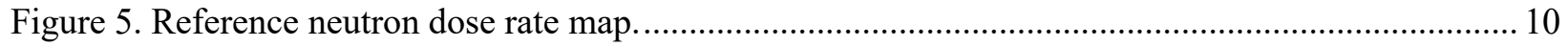

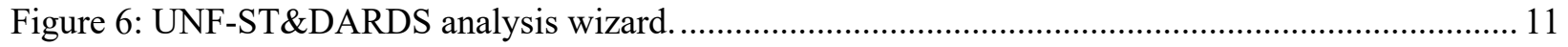

Figure 7: UNF-ST\&DARDS analysis wizard showing irradiation parameter selection options................ 12

Figure 8: UNF-ST\&DARDS analysis wizard showing user-specified canister loading map................... 13

Figure 9: UNF-ST\&DARDS analysis wizard showing different analysis options for a canister.............. 14

Figure 10: UNF-ST\&DARDS analysis wizard for executing an analysis............................................ 15

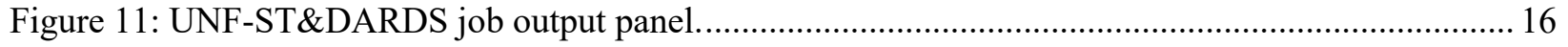

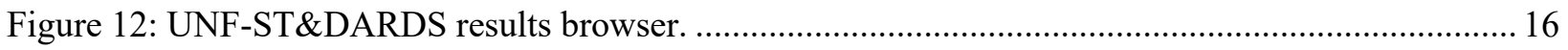




\section{LIST OF TABLES}

Table 1. Dose rate locations and tally mesh characteristics ............................................................ 5

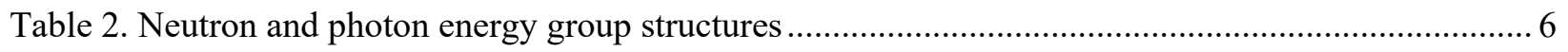

Table 3. Neutron source strength as a function of energy group and fuel assembly axial zone .................. 6

Table 4. Photon source strength as a function of energy group and fuel assembly axial zone................... 7

Table 5. Maximum dose rate values for each tally region obtained with the reference and on-the-

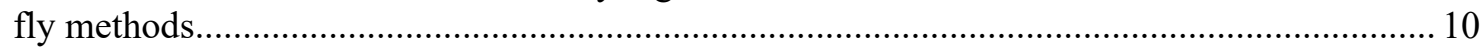




\section{ACRONYMS}

$3 \mathrm{D}$

ORNL

MTU

PWR

SFWD

SNF

UNF-ST\&DARDS 3-dimensional

Oak Ridge National Laboratory

metric ton of uranium

pressurized water reactor

Spent Fuel and Waste Disposition

spent nuclear fuel

Used Nuclear Fuel—Storage, Transportation \& Disposal Analysis Resource and Data System 
This page is intentionally left blank. 


\section{DEMONSTRATION OF THE ON-THE-FLY SHIELDING ANALYSIS METHOD}

\section{INTRODUCTION}

The Used Nuclear Fuel—Storage, Transportation \& Disposal Analysis Resource and Data System (UNFST\&DARDS) [1] is a comprehensive data and analysis capability that has been developed as a foundational waste management system resource for the US Department of Energy Office of Nuclear Energy (DOE-NE) through a collaborative effort of multiple national laboratories and industry participants. UNF-ST\&DARDS provides a unified domestic spent nuclear fuel (SNF) system database, referred to as the "Unified Database." The database is integrated with nuclear analysis capabilities (e.g., the SCALE [2] code system) to provide nuclear safety assessments for SNF storage and transportation systems based on actual characteristics of as-loaded SNF (e.g., fuel assembly average burnup, enrichment, and decay time).

Dose rates in the external regions of an SNF transportation package/storage cask are typically determined with a model that describes the system and the actual contents (i.e., materials, geometry, and radiation sources). This calculation method, referred to as the "reference method" in this report, requires a single dose rate calculation for each as-loaded canister. Radiation sources generated for each SNF assembly based on actual assembly average burnup and an axial burnup profile are used in the reference calculations. This method is currently used in UNF-ST\&DARDS to determine a three-dimensional (3D) dose rate map for an as-loaded SNF transportation package/storage cask.

A different method, referred to as the "on-the-fly" shielding analysis method, has been proposed [3]. The on-the-fly shielding analysis method consists of three separate steps:

1. determining dose rates external to a SNF transportation/storage system that are produced by a single particle (i.e., either a neutron, primary photon, secondary photon from neutron interactions, or photon from activation source decay) emitted within an energy group from a geometry region of the SNF assemblies;

2. multiplying the dose rates from the previous step by the actual radiation source strength in each energy group and SNF spatial region; and

3. summing the resulting dose rate values for all energy groups and geometry regions.

Therefore, the dose rates from step 1 are independent of radiation sources associated with actual fuel assembly loadings. These dose rates become specific to the transportation package/storage cask at the end of step 3. The step 1 calculations, performed with a Monte Carlo radiation transport code, are computationally expensive. Steps 2 and 3 of this method are very fast; hence they are characterized as onthe-fly analyses. However, the results of the prerequisite Monte Carlo calculations are saved in a library and can subsequently be used to determine dose rates for as-loaded systems or to analyze the effects of various SNF loading arrangements on external cask dose rates. The method facilitates the selection of SNF assemblies that qualify for loading based on regulatory dose rate limits.

The on-the-fly method is demonstrated in this report for an SNF storage cask loaded with identical pressurized water reactor (PWR) SNF assemblies. Method verification is performed by comparison with reference dose rate values. The demonstration is limited to dose rates produced by gamma and neutron radiation emitted from the active fuel region, which are main contributors to external dose rates. Gamma dose rates produced by activation sources in assembly hardware materials or secondary gamma radiation produced by neutron capture in fuel and structural materials are not analyzed in this report. However, application of the on-the-fly shielding analysis method to these types of radiation sources is straightforward and will be implemented in future dose rate calculations. 
Section 2 provides details on the computational model, methods, and tools used to demonstrate the onthe-fly method. Results of the dose rate calculations and implementation of the on-the-fly method in UNF-ST\&DARDS are presented in Section 3. Conclusions are provided in Section 4. 


\section{ANALYSIS METHODS, MODELS, AND COMPUTATIONAL TOOLS 2.1 On-the-fly Method}

The on-the-fly method is used to determine dose rates in the external regions of an SNF transportation package/storage cask. To apply this method, radiation source regions and particle energy ranges are discretized into a reasonable number of source spatial regions and energy groups. Then dose rates per particle (i.e., either neutron or photon), per energy group, and per source spatial region are calculated with a Monte Carlo radiation transport code.

The Monte Carlo dose rate estimate for each voxel of a spatial mesh may be denoted as $\dot{D}_{v, r, g}$, where the indices $v, r$, and $g$ denote the mesh voxel, source region, and energy group, respectively. The total dose rate produced in a mesh voxel by a type of particle is calculated with Eq. (1):

$$
\dot{D}_{v, \text { total }}=\sum_{r=1}^{n r} \sum_{g=1}^{n g} \dot{D}_{v, r, g} \cdot S_{r, g}
$$

where

$S_{r, g}$ is the source strength for source region $r$ and energy group $g ; n r$ is the total number of source regions; and $n g$ is the total number of energy groups.

The relative statistical uncertainty associated with the total dose rate produced in a mesh voxel, $R E_{v, \text { total }}$, is calculated with Eq. (2):

$$
R E_{v, \text { total }}=\frac{\left(\sum_{r=1}^{n r} \sum_{g=1}^{n g}\left(\dot{D}_{v, r, g} \cdot R E_{v, r, g}\right)^{2}\right)^{1 / 2}}{\dot{D}_{v, \text { total }}}
$$

\subsection{SCALE Code System}

The SCALE code system [2] was used to perform radiation source term and dose rate calculations for a representative SNF storage cask. Assembly-specific radiation source terms were generated with ORIGAMI, a SCALE code for calculating nuclide inventories, decay heat, and radiation source terms for SNF assemblies with axial and radial burnup variations. ORIGAMI uses ORIGEN cross-section libraries specifically developed for UNF-ST\&DARDS bounding analyses of representative fuel assembly types. Dose rate calculations were performed with MAVRIC [4], the SCALE Monte Carlo radiation transport sequence for shielding analyses with automated variance reduction capabilities. The MAVRIC feature "fromSource" was used to obtain dose rate values produced by each individual radiation source specified in an input file (e.g., a source in each of the 18 axial zones of the active fuel). The MAVRIC postprocessing utility mt2ascii was used to convert a 3dmap file to an ASCII file for further processing using a Python script.

\subsection{HI-STORM FW Storage Cask Model}

The on-the-fly shielding analysis method is demonstrated for the HI-STORM FW storage cask [5]. Inside the cask is a multi-purpose MPC-37 canister containing 37 identical PWR fuel assemblies with respect to fuel type, materials, and irradiation and decay parameters. Figure 1 (a) shows the 3D cask geometry model with the front-right corner removed, which enables a view of the assembly model featuring 18 axial fuel zones. A horizontal cross sectional view of the cask model is shown in Figure 1 (b).

Geometry models for these cask and canister types are available in the UNF-ST\&DARD template repository. Reference dose rates were calculated at the radial and top cask surfaces and at $1 \mathrm{~m}$ from the 
radial and top cask surfaces (see Figure 2) using 11 cylindrical meshes and corresponding mesh tallies. The characteristics of the cylindrical meshes are presented in Table 1.

New specific shielding analysis templates were developed to enable the automatic creation of MAVRIC input files for step 1 of the on-the-fly analysis. These new templates primarily specify radiation sources, cylindrical meshes, and mesh tallies specific to the on-the-fly analysis method. A MAVRIC input file was generated for each fuel assembly and each energy group. Therefore, the number of MAVRIC input files created was 481, i.e., 37 fuel assemblies $\times 13$ total photon and neutron energy groups. Each input file specified one particle in each of the 18 axial zones of the active fuel. A mesh tally was defined for each dose location (see Table 1) and source particle using the "fromSource" feature available in MAVRIC. Therefore, the total number of mesh tallies in each MAVRIC input file was 198, i.e., 11 dose rate locations $\times 18$ sources. The individual mesh tallies were specified in place of a single all-inclusive mesh tally to reduce the total size of the output 3dmap files from the MAVRIC calculations. However, the total number of individual 3dmap dose rate files produced by the MAVRIC calculations increased considerably to 95,238 , i.e., 37 fuel assemblies $\times 13$ total photon and neutron energy groups $\times 18$ fuel axial zones $\times 11$ mesh tallies.

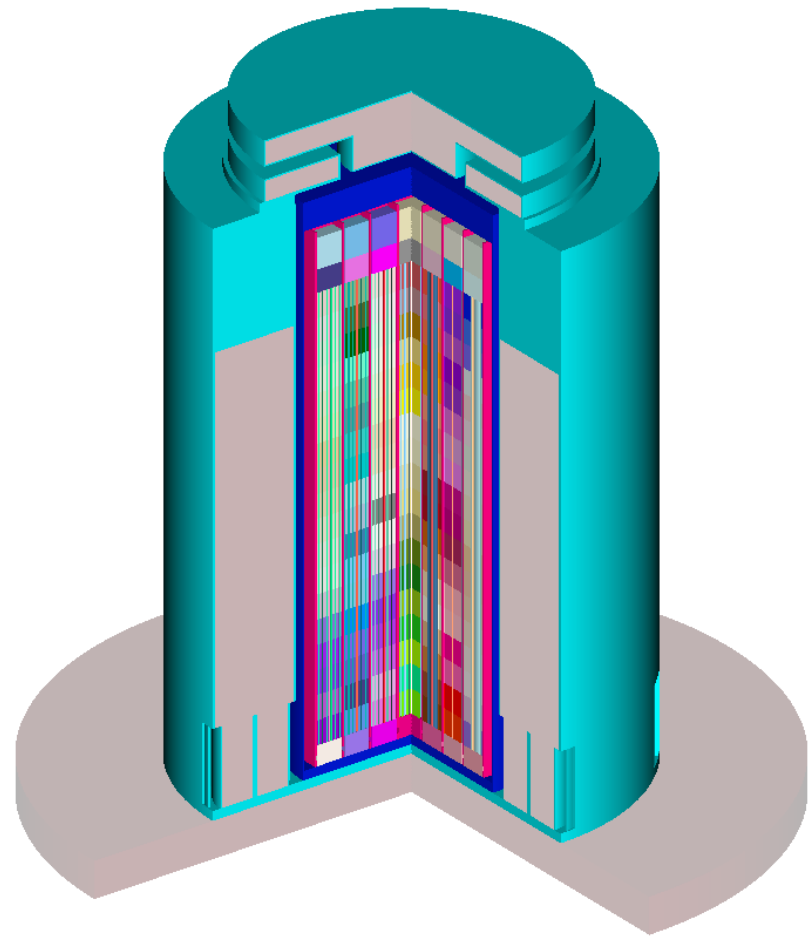

(a)

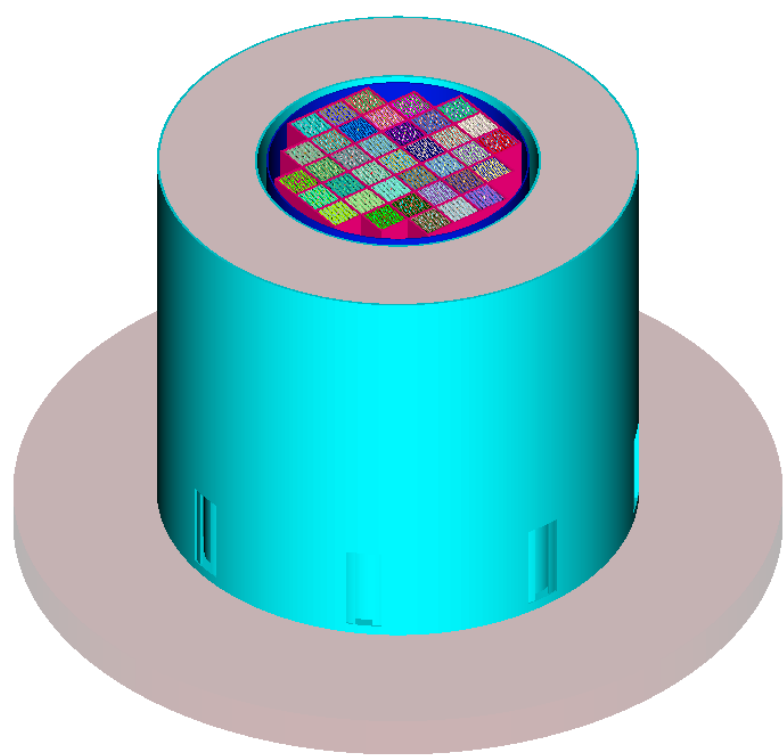

(b)

Figure 1. Vertical (a) and horizontal (b) cross-sectional views of the HI-STORM FW geometry model. 


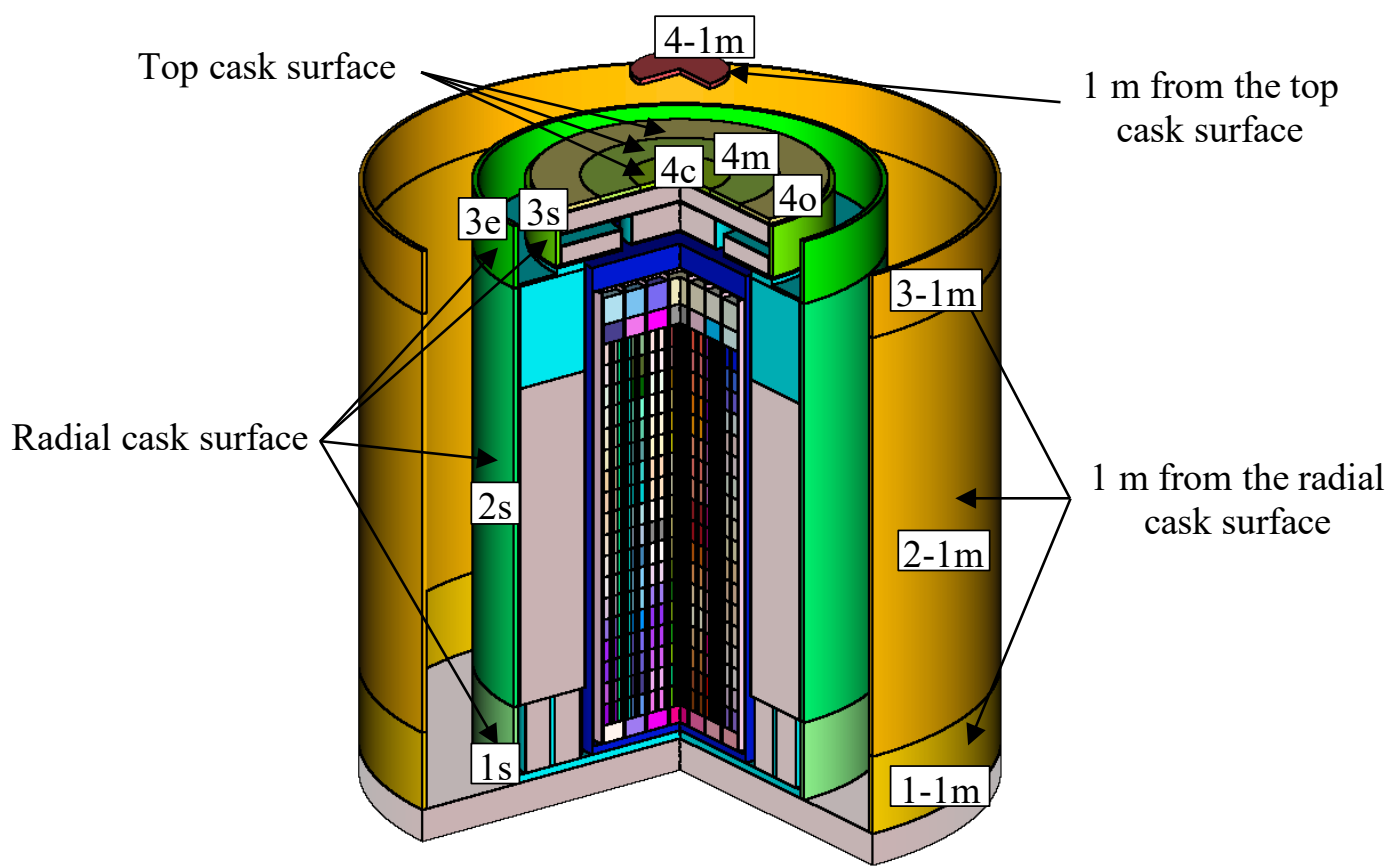

Figure 2. Dose rate locations.

Table 1. Dose rate locations and tally mesh characteristics

\begin{tabular}{|l|c|c|c|c|c|}
\hline Location & Dose point & $\begin{array}{c}\text { Radial } \\
\text { segments }\end{array}$ & $\begin{array}{c}\text { Angular } \\
\text { segments }\end{array}$ & $\begin{array}{c}\text { Axial } \\
\text { segments }\end{array}$ & $\begin{array}{c}\text { Total number } \\
\text { of voxels }\end{array}$ \\
\hline Cask surface & DP1-surface & 1 & 33 & 3 & 99 \\
\hline Cask surface & DP2-surface & 1 & 24 & 40 & 960 \\
\hline Cask surface & DP3e & 1 & 24 & 5 & 120 \\
\hline Cask surface & DP3s & 1 & 24 & 4 & 96 \\
\hline Cask surface & DP4c & 2 & 24 & 1 & 48 \\
\hline Cask surface & DP4m & 3 & 24 & 1 & 72 \\
\hline Cask surface & DP4o & 4 & 24 & 1 & 96 \\
\hline 1 m from cask surface & DP1-1m & 1 & 24 & 3 & 72 \\
\hline 1 m from cask surface & DP2-1m & 1 & 24 & 40 & 960 \\
\hline 1 m from cask surface & DP3-1m & 1 & 24 & 5 & 120 \\
\hline 1 m from cask surface & DP4-1m & 2 & 24 & 1 & 48 \\
\hline
\end{tabular}

\subsection{SNF Radiation Sources}

The fuel assembly model was a Crystal River B\&W $15 \times 15$ fuel assembly type with an initial enrichment of $4.26 \mathrm{wt} \%{ }^{235} \mathrm{U}$, irradiated to an average assembly burnup of $50,788.7 \mathrm{MWd} / \mathrm{MTU}$, and cooled for 5 years after irradiation. The initial MTU (metric tons of uranium) of this assembly was 0.4654 . The photon and neutron energy group structures, taken from the HI-STORM FW Final Safety Analysis Report [5], Tables 5.2.2 and 5.2.11, respectively, are shown in Table 2. The neutron and photon source strengths for each energy group and fuel assembly axial node are presented in Table 3 and Table 4, respectively. 
Table 2. Neutron and photon energy group structures

\begin{tabular}{|c|c|c|c|c|c|}
\hline & \multicolumn{2}{|c|}{ Neutrons } & & \multicolumn{2}{c|}{ Photon } \\
\hline $\begin{array}{c}\text { Neutron } \\
\text { energy group }\end{array}$ & $\begin{array}{c}\text { Lower energy } \\
(\mathbf{M e V})\end{array}$ & $\begin{array}{c}\text { Upper energy } \\
(\mathbf{M e V})\end{array}$ & $\begin{array}{c}\text { Photon energy } \\
\text { group }\end{array}$ & $\begin{array}{c}\text { Lower energy } \\
(\mathbf{M e V})\end{array}$ & $\begin{array}{c}\text { Upper energy } \\
(\mathbf{M e V})\end{array}$ \\
\hline 1 & 6.43 & 20.0 & 1 & 2.5 & 3.0 \\
\hline 2 & 3.0 & 6.43 & 2 & 2.0 & 2.5 \\
\hline 3 & 1.85 & 3.0 & 3 & 1.5 & 2.0 \\
\hline 4 & 1.4 & 1.85 & 4 & 1.0 & 1.5 \\
\hline 5 & 0.9 & 1.4 & 5 & 0.7 & 1.0 \\
\hline 6 & 0.4 & 0.9 & 6 & 0.45 & 0.7 \\
\hline 7 & 0.1 & 0.4 & - & - & - \\
\hline
\end{tabular}

Table 3. Neutron source strength as a function of energy group and fuel assembly axial zone

\begin{tabular}{|c|c|c|c|c|c|c|c|c|}
\hline & \multicolumn{7}{|c|}{ Energy group $^{\boldsymbol{a}}$} & \\
\hline $\begin{array}{c}\text { Assembly } \\
\text { axial zone }^{b}\end{array}$ & $\mathbf{1}$ & $\mathbf{2}$ & $\mathbf{3}$ & $\mathbf{4}$ & $\mathbf{5}$ & $\mathbf{6}$ & $\mathbf{7}$ & Total \\
\hline 1 & $1.075 \mathrm{E}+05$ & $1.132 \mathrm{E}+06$ & $1.253 \mathrm{E}+06$ & $6.690 \mathrm{E}+05$ & $8.358 \mathrm{E}+05$ & $8.363 \mathrm{E}+05$ & $3.835 \mathrm{E}+05$ & $5.22 \mathrm{E}+06$ \\
\hline 2 & $5.438 \mathrm{E}+05$ & $5.659 \mathrm{E}+06$ & $6.207 \mathrm{E}+06$ & $3.345 \mathrm{E}+06$ & $4.193 \mathrm{E}+06$ & $4.198 \mathrm{E}+06$ & $1.925 \mathrm{E}+06$ & $2.61 \mathrm{E}+07$ \\
\hline 3 & $8.111 \mathrm{E}+05$ & $8.426 \mathrm{E}+06$ & $9.230 \mathrm{E}+06$ & $4.980 \mathrm{E}+06$ & $6.244 \mathrm{E}+06$ & $6.253 \mathrm{E}+06$ & $2.867 \mathrm{E}+06$ & $3.88 \mathrm{E}+07$ \\
\hline 4 & $8.965 \mathrm{E}+05$ & $9.309 \mathrm{E}+06$ & $1.020 \mathrm{E}+07$ & $5.502 \mathrm{E}+06$ & $6.900 \mathrm{E}+06$ & $6.910 \mathrm{E}+06$ & $3.168 \mathrm{E}+06$ & $4.29 \mathrm{E}+07$ \\
\hline 5 & $9.118 \mathrm{E}+05$ & $9.467 \mathrm{E}+06$ & $1.037 \mathrm{E}+07$ & $5.595 \mathrm{E}+06$ & $7.017 \mathrm{E}+06$ & $7.027 \mathrm{E}+06$ & $3.221 \mathrm{E}+06$ & $4.36 \mathrm{E}+07$ \\
\hline 6 & $9.057 \mathrm{E}+05$ & $9.404 \mathrm{E}+06$ & $1.030 \mathrm{E}+07$ & $5.558 \mathrm{E}+06$ & $6.970 \mathrm{E}+06$ & $6.980 \mathrm{E}+06$ & $3.200 \mathrm{E}+06$ & $4.33 \mathrm{E}+07$ \\
\hline 7 & $8.935 \mathrm{E}+05$ & $9.278 \mathrm{E}+06$ & $1.016 \mathrm{E}+07$ & $5.483 \mathrm{E}+06$ & $6.876 \mathrm{E}+06$ & $6.886 \mathrm{E}+06$ & $3.157 \mathrm{E}+06$ & $4.27 \mathrm{E}+07$ \\
\hline 8 & $8.784 \mathrm{E}+05$ & $9.122 \mathrm{E}+06$ & $9.990 \mathrm{E}+06$ & $5.391 \mathrm{E}+06$ & $6.761 \mathrm{E}+06$ & $6.770 \mathrm{E}+06$ & $3.104 \mathrm{E}+06$ & $4.20 \mathrm{E}+07$ \\
\hline 9 & $8.694 \mathrm{E}+05$ & $9.029 \mathrm{E}+06$ & $9.889 \mathrm{E}+06$ & $5.336 \mathrm{E}+06$ & $6.692 \mathrm{E}+06$ & $6.702 \mathrm{E}+06$ & $3.072 \mathrm{E}+06$ & $4.16 \mathrm{E}+07$ \\
\hline 10 & $8.694 \mathrm{E}+05$ & $9.029 \mathrm{E}+06$ & $9.889 \mathrm{E}+06$ & $5.336 \mathrm{E}+06$ & $6.692 \mathrm{E}+06$ & $6.702 \mathrm{E}+06$ & $3.072 \mathrm{E}+06$ & $4.16 \mathrm{E}+07$ \\
\hline 11 & $8.724 \mathrm{E}+05$ & $9.060 \mathrm{E}+06$ & $9.923 \mathrm{E}+06$ & $5.355 \mathrm{E}+06$ & $6.715 \mathrm{E}+06$ & $6.725 \mathrm{E}+06$ & $3.083 \mathrm{E}+06$ & $4.17 \mathrm{E}+07$ \\
\hline 12 & $8.754 \mathrm{E}+05$ & $9.091 \mathrm{E}+06$ & $9.956 \mathrm{E}+06$ & $5.373 \mathrm{E}+06$ & $6.738 \mathrm{E}+06$ & $6.747 \mathrm{E}+06$ & $3.093 \mathrm{E}+06$ & $4.19 \mathrm{E}+07$ \\
\hline 13 & $8.724 \mathrm{E}+05$ & $9.060 \mathrm{E}+06$ & $9.923 \mathrm{E}+06$ & $5.355 \mathrm{E}+06$ & $6.715 \mathrm{E}+06$ & $6.725 \mathrm{E}+06$ & $3.083 \mathrm{E}+06$ & $4.17 \mathrm{E}+07$ \\
\hline 14 & $8.458 \mathrm{E}+05$ & $8.785 \mathrm{E}+06$ & $9.622 \mathrm{E}+06$ & $5.192 \mathrm{E}+06$ & $6.510 \mathrm{E}+06$ & $6.520 \mathrm{E}+06$ & $2.989 \mathrm{E}+06$ & $4.05 \mathrm{E}+07$ \\
\hline 15 & $7.692 \mathrm{E}+05$ & $7.992 \mathrm{E}+06$ & $8.757 \mathrm{E}+06$ & $4.724 \mathrm{E}+06$ & $5.923 \mathrm{E}+06$ & $5.931 \mathrm{E}+06$ & $2.719 \mathrm{E}+06$ & $3.68 \mathrm{E}+07$ \\
\hline 16 & $5.525 \mathrm{E}+05$ & $5.750 \mathrm{E}+06$ & $6.306 \mathrm{E}+06$ & $3.399 \mathrm{E}+06$ & $4.260 \mathrm{E}+06$ & $4.265 \mathrm{E}+06$ & $1.955 \mathrm{E}+06$ & $2.65 \mathrm{E}+07$ \\
\hline 17 & $1.820 \mathrm{E}+05$ & $1.907 \mathrm{E}+06$ & $2.102 \mathrm{E}+06$ & $1.127 \mathrm{E}+06$ & $1.410 \mathrm{E}+06$ & $1.411 \mathrm{E}+06$ & $6.471 \mathrm{E}+05$ & $8.79 \mathrm{E}+06$ \\
\hline 18 & $2.317 \mathrm{E}+04$ & $2.512 \mathrm{E}+05$ & $2.844 \mathrm{E}+05$ & $1.485 \mathrm{E}+05$ & $1.841 \mathrm{E}+05$ & $1.839 \mathrm{E}+05$ & $8.442 \mathrm{E}+04$ & $1.16 \mathrm{E}+06$ \\
\hline
\end{tabular}

${ }^{a}$ See Table 2 for group energy bounds.

${ }^{b}$ Axial zones from the bottom to the top of the active fuel region. 
Table 4. Photon source strength as a function of energy group and fuel assembly axial zone

\begin{tabular}{|c|c|c|c|c|c|c|c|}
\hline & \multicolumn{6}{|c|}{ Energy group $^{a}$} & \\
\hline Assembly axial zone & 1 & 2 & 3 & 4 & 5 & 6 & Total \\
\hline 1 & $6.50 \mathrm{E}+09$ & $9.23 \mathrm{E}+10$ & $1.85 \mathrm{E}+11$ & $7.33 \mathrm{E}+12$ & $2.70 \mathrm{E}+13$ & $1.15 \mathrm{E}+14$ & $1.49 \mathrm{E}+14$ \\
\hline 2 & $1.14 \mathrm{E}+10$ & $1.38 \mathrm{E}+11$ & $3.25 \mathrm{E}+11$ & $1.28 \mathrm{E}+13$ & $5.53 \mathrm{E}+13$ & $1.90 \mathrm{E}+14$ & $2.59 \mathrm{E}+14$ \\
\hline 3 & $1.32 \mathrm{E}+10$ & $1.54 \mathrm{E}+11$ & $3.74 \mathrm{E}+11$ & $1.48 \mathrm{E}+13$ & $6.66 \mathrm{E}+13$ & $2.18 \mathrm{E}+14$ & $3.00 \mathrm{E}+14$ \\
\hline 4 & $1.37 \mathrm{E}+10$ & $1.59 \mathrm{E}+11$ & $3.87 \mathrm{E}+11$ & $1.53 \mathrm{E}+13$ & $6.99 \mathrm{E}+13$ & $2.26 \mathrm{E}+14$ & $3.12 \mathrm{E}+14$ \\
\hline 5 & $1.38 \mathrm{E}+10$ & $1.59 \mathrm{E}+11$ & $3.89 \mathrm{E}+11$ & $1.54 \mathrm{E}+13$ & $7.04 \mathrm{E}+13$ & $2.27 \mathrm{E}+14$ & $3.14 \mathrm{E}+14$ \\
\hline 6 & $1.38 \mathrm{E}+10$ & $1.59 \mathrm{E}+11$ & $3.88 \mathrm{E}+11$ & $1.54 \mathrm{E}+13$ & $7.02 \mathrm{E}+13$ & $2.27 \mathrm{E}+14$ & $3.13 \mathrm{E}+14$ \\
\hline 7 & $1.37 \mathrm{E}+10$ & $1.58 \mathrm{E}+11$ & $3.87 \mathrm{E}+11$ & $1.53 \mathrm{E}+13$ & $6.97 \mathrm{E}+13$ & $2.26 \mathrm{E}+14$ & $3.11 \mathrm{E}+14$ \\
\hline 8 & $1.36 \mathrm{E}+10$ & $1.58 \mathrm{E}+11$ & $3.84 \mathrm{E}+11$ & $1.52 \mathrm{E}+13$ & $6.92 \mathrm{E}+13$ & $2.24 \mathrm{E}+14$ & $3.09 \mathrm{E}+14$ \\
\hline 9 & $1.36 \mathrm{E}+10$ & $1.57 \mathrm{E}+11$ & $3.83 \mathrm{E}+11$ & $1.51 \mathrm{E}+13$ & $6.89 \mathrm{E}+13$ & $2.23 \mathrm{E}+14$ & $3.08 \mathrm{E}+14$ \\
\hline 10 & $1.36 \mathrm{E}+10$ & $1.57 \mathrm{E}+11$ & $3.83 \mathrm{E}+11$ & $1.51 \mathrm{E}+13$ & $6.89 \mathrm{E}+13$ & $2.23 \mathrm{E}+14$ & $3.08 \mathrm{E}+14$ \\
\hline 11 & $1.36 \mathrm{E}+10$ & $1.57 \mathrm{E}+11$ & $3.83 \mathrm{E}+11$ & $1.52 \mathrm{E}+13$ & $6.90 \mathrm{E}+13$ & $2.24 \mathrm{E}+14$ & $3.08 \mathrm{E}+14$ \\
\hline 12 & $1.36 \mathrm{E}+10$ & $1.58 \mathrm{E}+11$ & $3.84 \mathrm{E}+11$ & $1.52 \mathrm{E}+13$ & $6.91 \mathrm{E}+13$ & $2.24 \mathrm{E}+14$ & $3.09 \mathrm{E}+14$ \\
\hline 13 & $1.36 \mathrm{E}+10$ & $1.57 \mathrm{E}+11$ & $3.83 \mathrm{E}+11$ & $1.52 \mathrm{E}+13$ & $6.90 \mathrm{E}+13$ & $2.24 \mathrm{E}+14$ & $3.08 \mathrm{E}+14$ \\
\hline 14 & $1.34 \mathrm{E}+10$ & $1.56 \mathrm{E}+11$ & $3.79 \mathrm{E}+11$ & $1.50 \mathrm{E}+13$ & $6.80 \mathrm{E}+13$ & $2.21 \mathrm{E}+14$ & $3.05 \mathrm{E}+14$ \\
\hline 15 & $1.30 \mathrm{E}+10$ & $1.52 \mathrm{E}+11$ & $3.67 \mathrm{E}+11$ & $1.45 \mathrm{E}+13$ & $6.50 \mathrm{E}+13$ & $2.14 \mathrm{E}+14$ & $2.94 \mathrm{E}+14$ \\
\hline 16 & $1.14 \mathrm{E}+10$ & $1.39 \mathrm{E}+11$ & $3.27 \mathrm{E}+11$ & $1.29 \mathrm{E}+13$ & $5.57 \mathrm{E}+13$ & $1.91 \mathrm{E}+14$ & $2.60 \mathrm{E}+14$ \\
\hline 17 & $7.75 \mathrm{E}+09$ & $1.05 \mathrm{E}+11$ & $2.22 \mathrm{E}+11$ & $8.75 \mathrm{E}+12$ & $3.39 \mathrm{E}+13$ & $1.34 \mathrm{E}+14$ & $1.77 \mathrm{E}+14$ \\
\hline 18 & $4.00 \mathrm{E}+09$ & $6.49 \mathrm{E}+10$ & $1.09 \mathrm{E}+11$ & $4.42 \mathrm{E}+12$ & $1.43 \mathrm{E}+13$ & $7.49 \mathrm{E}+13$ & $9.37 \mathrm{E}+13$ \\
\hline
\end{tabular}

${ }^{a}$ See Table 2 for group energy bounds.

${ }^{b}$ Axial zones from the bottom to the top of the active fuel region.

\subsection{Python Script}

Two Python programs were developed for processing the MAVRIC results and performing the dose calculations using Eqs. (1) and (2).

Data processor code: The Python data processor code uses the directory structure shown in Figure 3. For the HI-STORM FW analysis, 11 tallies were used. As shown in Figure 3, the directory structure includes a directory for each fuel assembly (denoted as a1 through a37). Eleven tally folders reside within each assembly directory. The name of a tally folder indicates the type of particle ( $n$ indicates neutron tallies, and $p$ indicates photon tallies) and a material mixture that identifies each folder. Each tally folder contains a .txt file for each group and axial segment. For example, 6 energy groups and 18 axial nodes were used for photon tally calculations and a photon tally folder contains $108(18 \times 6)$.txt files. The name of a .txt file includes relevant information about the type of particle (i.e., $n$ or p), dose rate location (e.g., DP4o), fuel assembly (e.g., a4), source axial location in the active fuel region (e.g., 1), and energy group (e.g., 5). For example, the txt file named n-DP4o-surf-a4-z1-eg5.txt contains dose rate values produced by one neutron at dose rate location DPo on the cask surface, where the neutron was emitted from the $1^{\text {st }}$ axial zone of the assembly a4, with energy within energy group 5 . Each .txt file contains tally mesh information and dose rate in $\mathrm{mrem} / \mathrm{h}$ per starting energy group and per location and corresponding 1 sigma uncertainty. The data processor code reads all the data from the .txt files and creates four Python dictionaries (Python data structure) for storing (1) the dose and uncertainty using tally $\rightarrow$ tally type (n/p) $\rightarrow$ axial tally segment $\rightarrow$ angular tally segment $\rightarrow$ radial tally segment $\rightarrow$ assembly ID $\rightarrow$ axial nodes $\rightarrow$ energy group, (2) the axial tally segments, (3) the radial tally segments, and (4) the angular (azimuthal) tally segments. These Python dictionaries are converted into binary files using a Python process called "pickling." These binary files are distributed with UNF-ST\&DARDS for on-the-fly dose analysis. 
On-the-fly dose calculator: This Python code unzips the pre-generated binary files mentioned above, reads the data, and combines them with user-specified sources for dose and uncertainty calculations using Eqs. (1) and (2). UNF-ST\&DARDS directly executes this Python code for on-the-fly dose analysis.

The Python codes were verified using Excel calculations and by comparison with the values obtained with MAVRIC post-processing utilities applied to the 3dmap files generated at step 1 of the on-the-fly method. The utility mtMultiplier was used to multiply the tally value by the source strength as a function of assembly, assembly axial location, and particle energy group. The utility mtAdder was used to sum up the resulting dose rate values over total number of assemblies, assembly axial locations, and energy groups.

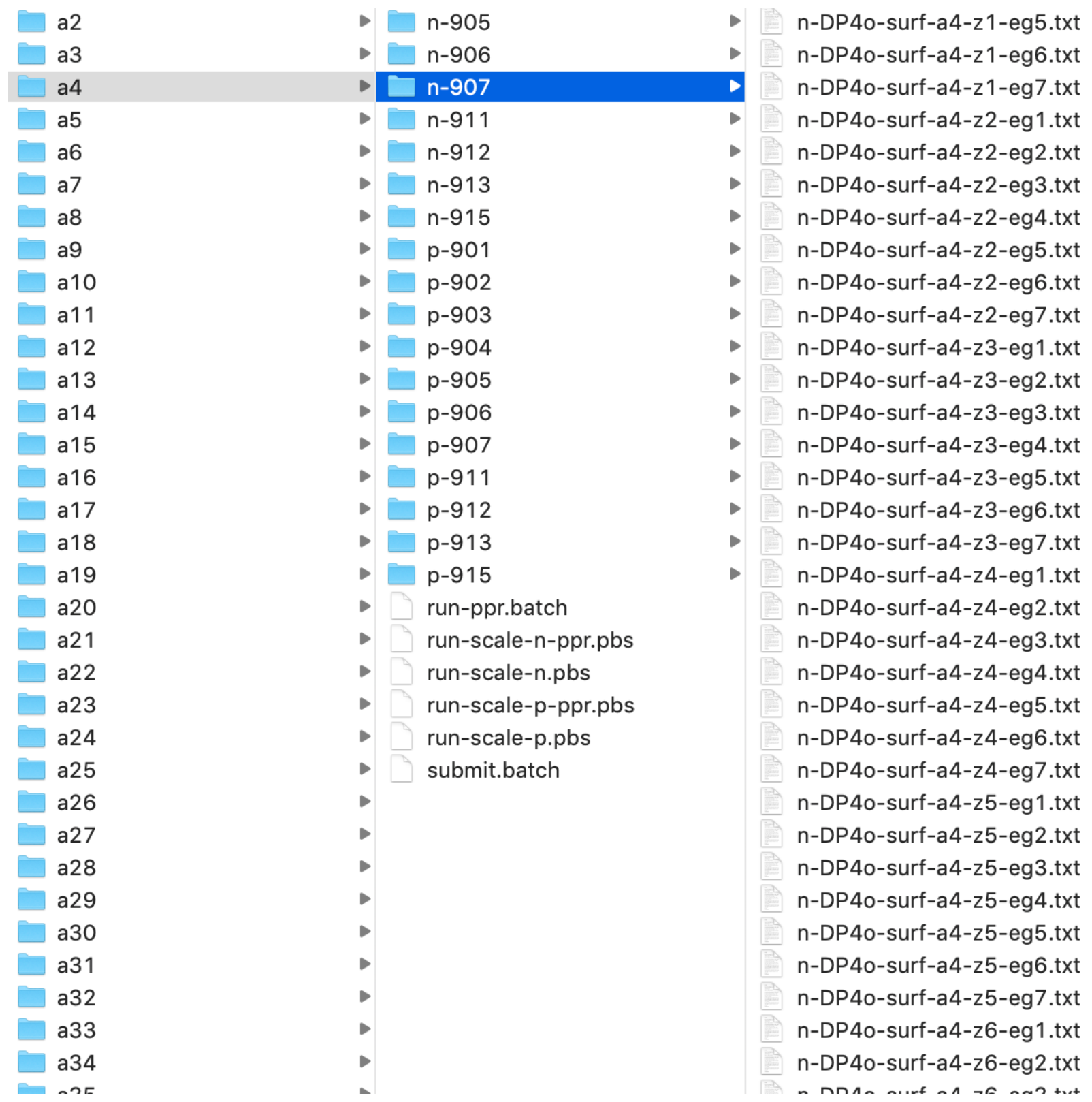

Figure 3: Directory structure used for MAVRIC data processing. 


\section{RESULTS}

Section 3.1 presents the verification of the on-the-fly shielding analysis method by comparison with reference dose rates for the HI-STORM FW model described in Section 2.3. Implementation of the onthe-fly shielding analysis method is described in Section 3.2.

\subsection{Dose Rate Calculation Results}

Reference dose rates were calculated at the radial and top cask surfaces and at $1 \mathrm{~m}$ from the radial and top cask surfaces (see Figure 2). The 3D dose rate maps in Figure 4 and Figure 5, respectively, show that the gamma dose rate is higher than the neutron dose rate in the external regions of the cask. For example, the gamma dose rate is up to two orders of magnitude higher than the neutron dose rate on the radial cask surface. The maximum total dose rate values at the cask surfaces and at $1 \mathrm{~m}$ from the cask surfaces are approximately $200 \mathrm{mrem} / \mathrm{h}$ and $60 \mathrm{mrem} / \mathrm{h}$, respectively.

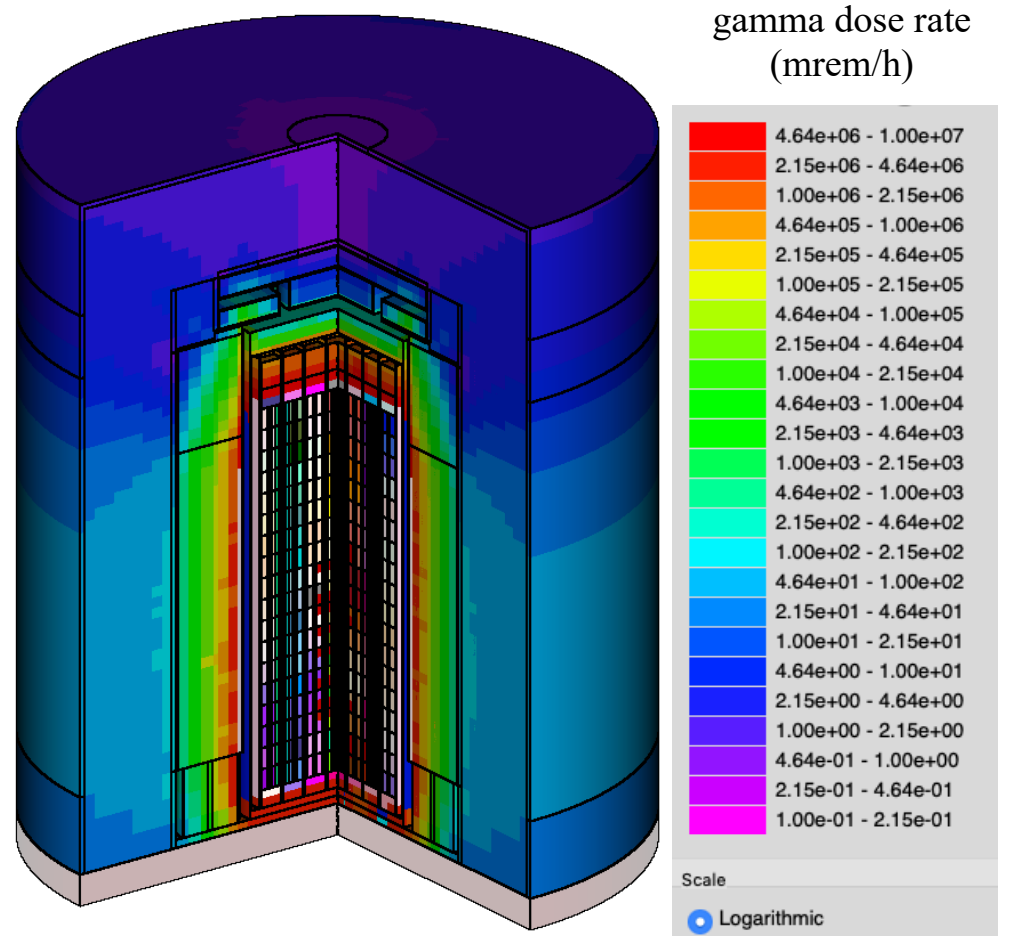

Figure 4. Reference gamma dose rate map. 


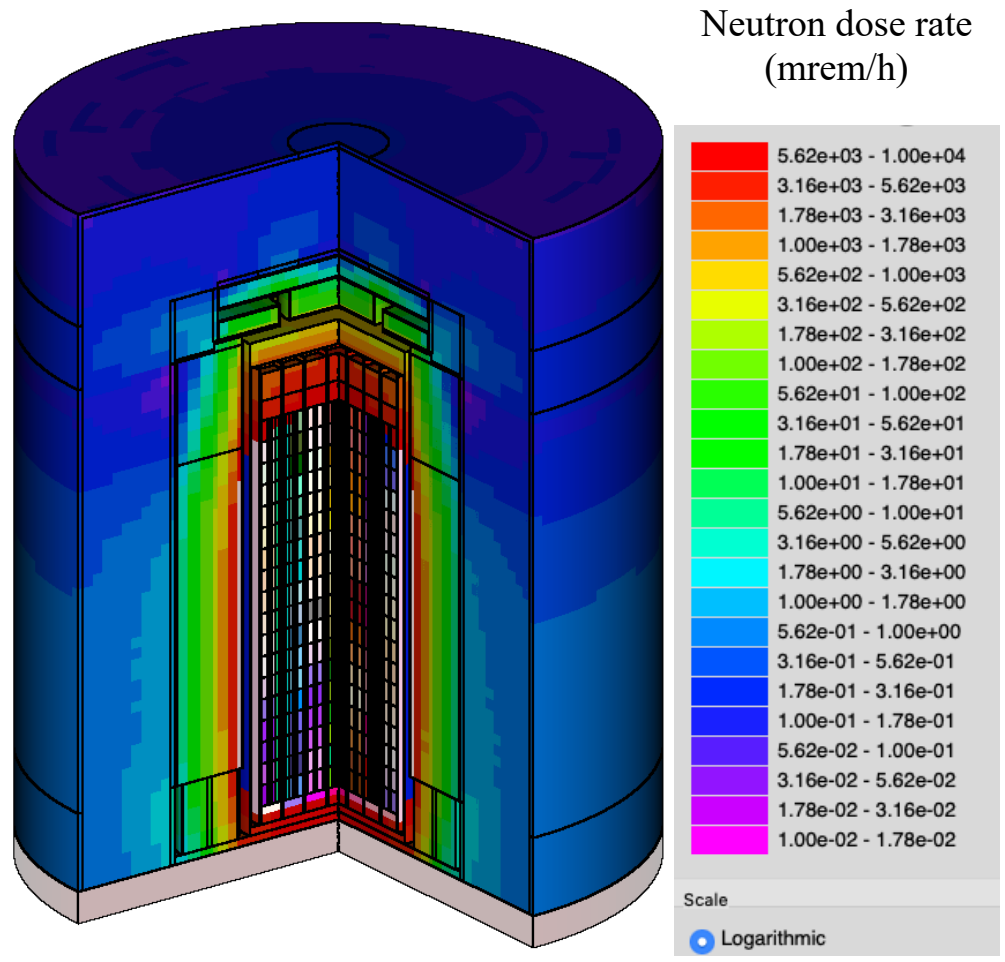

Figure 5. Reference neutron dose rate map.

The maximum total dose rate values for each tally region (see Figure 2) obtained with the on-the-fly and the reference methods are presented in Table 5. A comparison of these values shows that the dose rate values produced by the on-the-fly method are within statistical uncertainties of the reference values.

Table 5. Maximum dose rate values for each tally region obtained with the reference and on-the-fly methods

\begin{tabular}{|c|c|c|c|c|}
\hline & \multicolumn{2}{|c|}{ Assembly 1 } & \multicolumn{2}{c|}{ Canister } \\
\hline Method & On-the-fly & Reference & \multicolumn{1}{c|}{ On-the-fly } & Reference \\
\hline Dose rate location & \multicolumn{3}{|c|}{ Maximum dose rate \pm 2 sigma (mrem/h) } \\
\hline DP1-surface & $55.14 \pm 9.05$ & $49.26 \pm 1.40$ & $215.37 \pm 20.57$ & $209.91 \pm 20.99$ \\
\hline DP1-1m & $14.98 \pm 0.19$ & $15.02 \pm 0.16$ & $45.67 \pm 0.75$ & $46.54 \pm 1.97$ \\
\hline DP2-surface & $52.48 \pm 0.96$ & $51.72 \pm 0.20$ & $121.15 \pm 1.26$ & $120.38 \pm 0.51$ \\
\hline DP2-1m & $22.33 \pm 0.27$ & $22.26 \pm 0.17$ & $63.73 \pm 0.35$ & $63.50 \pm 0.17$ \\
\hline DP3s & $2.89 \pm 0.34$ & $2.82 \pm 0.09$ & $14.82 \pm 0.72$ & $14.76 \pm 0.63$ \\
\hline DP3e & $1.22 \pm 0.06$ & $1.23 \pm 0.02$ & $9.33 \pm 0.10$ & $9.35 \pm 0.09$ \\
\hline DP3-1m & $2.06 \pm 0.04$ & $1.97 \pm 0.01$ & $6.91 \pm 0.06$ & $6.72 \pm 0.03$ \\
\hline DP4c-surface & $0.018 \pm 0.001$ & $0.019 \pm 0.001$ & $0.33 \pm 0.02$ & $0.33 \pm 0.01$ \\
\hline DP4m-surface & $0.23 \pm 0.04$ & $0.24 \pm 0.02$ & $1.39 \pm 0.08$ & $1.35 \pm 0.03$ \\
\hline DP4o-surface & $1.08 \pm 0.08$ & $1.07 \pm 0.02$ & $4.09 \pm 0.60$ & $3.90 \pm 0.21$ \\
\hline DP4-1m & $0.064 \pm 0.002$ & $0.066 \pm 0.002$ & $0.74 \pm 0.02$ & $0.74 \pm 0.01$ \\
\hline
\end{tabular}




\subsection{UNF-ST\&DARDS Implementation}

The methodology has been implemented in UNF-ST\&DARDS. UNF-ST\&DARDS uses precalculated onthe-fly binary libraries generated by a Python data processor, as described in Section 2.5. These libraries are stored in the data/on_the_fly folder located at the UNF-ST\&DARDS root. Users can initiate on-thefly dose analysis by selecting Custom $\rightarrow$ Canister Criticality, Decay, and Shielding on the Analysis Wizard as shown in Figure 6.

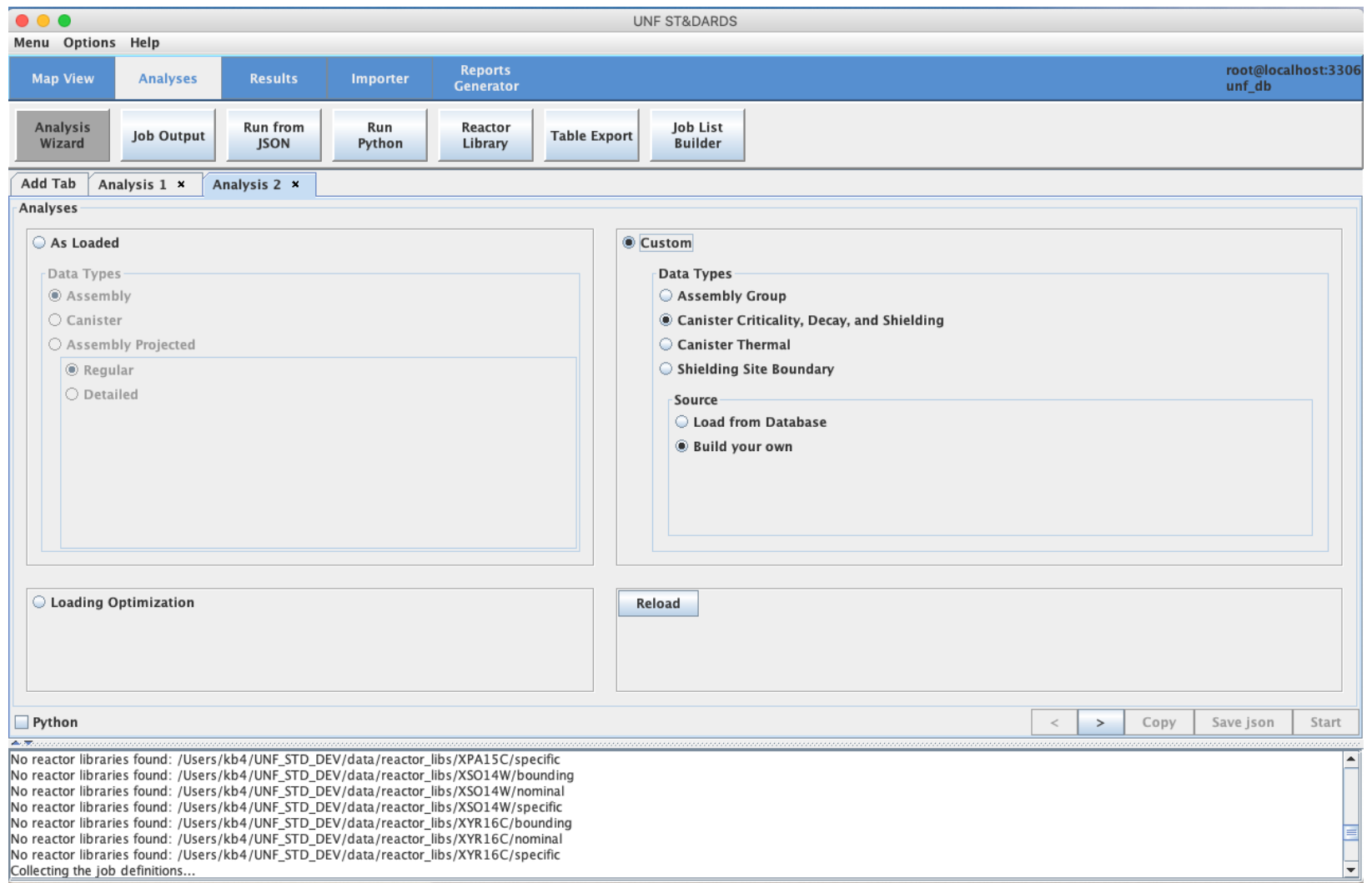

Figure 6: UNF-ST\&DARDS analysis wizard.

The next button $(>)$ in the lower right corner (Figure 6) takes users to the next page/panel of the analysis wizard, where they are directed to select a pre-generated reactor library (irradiation parameter) for source term analysis, as shown in Figure 7. Figure 7 shows that a bounding library/irradiation parameter type option has been selected for this example. 


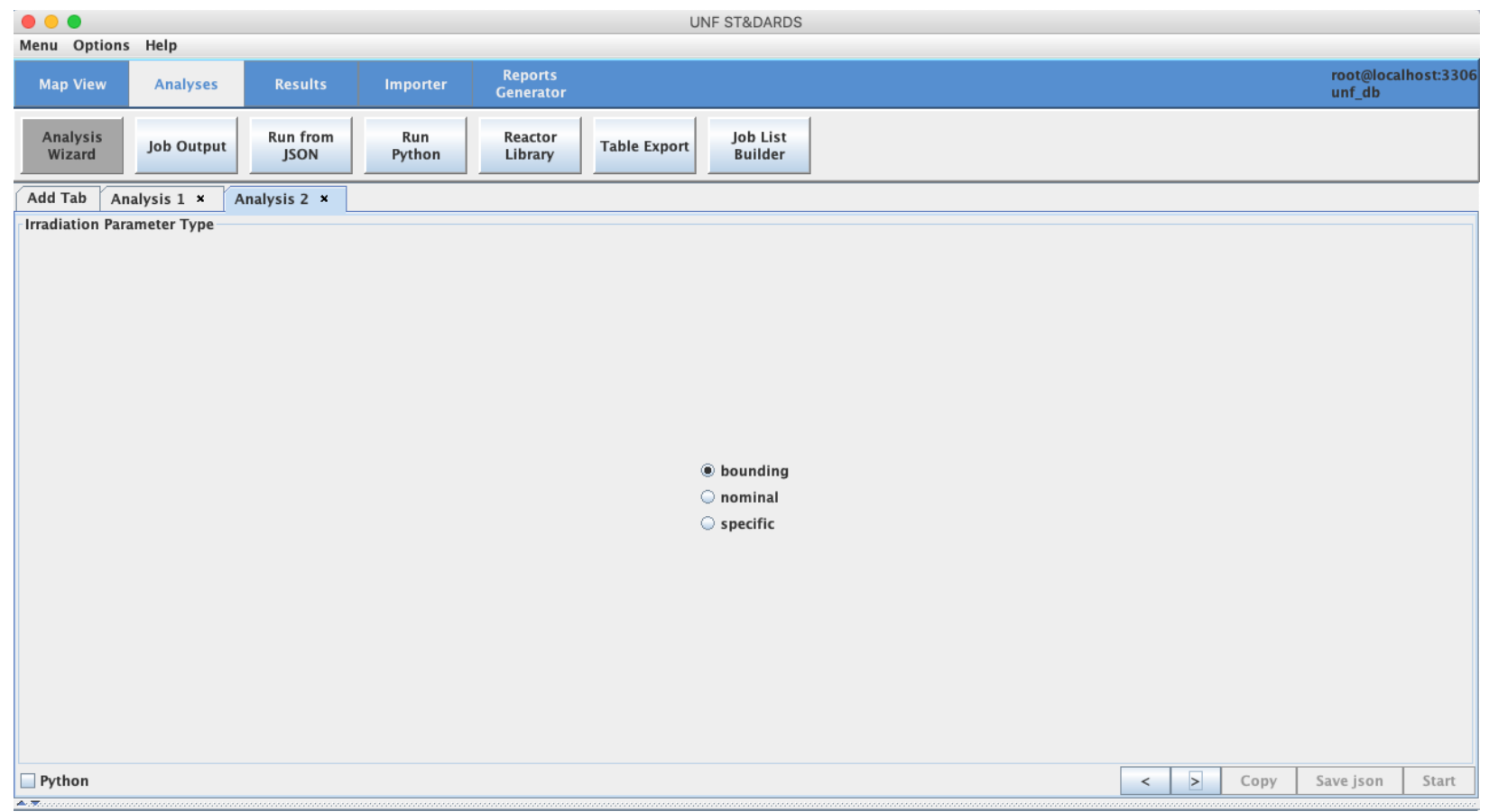

Figure 7: UNF-ST\&DARDS analysis wizard showing irradiation parameter selection options.

On the next page/panel, users are directed to select a canister (MPC-37 in this example); provide a canister ID or a case name; and select the assembly type and radiation source parameters including enrichment, uranium mass, cooling time, and burnup as shown in Figure 8. Users can select a default burnup profile or add a custom profile by clicking the Add Custom button. Initial on-the-fly implementation is for a PWR system (MPC-37 in HI-STORM FW) with 18 axial zones. Any custom burnup profile must contain 18 axial zones. There is an option for adding components such as burnable poison rod assemblies, but it is not implemented in this initial development phase. Users can provide the number of assemblies ( 37 in this example) in the Inventory Count box and press "enter" to generate a loading map, as shown on the right panel (Figure 8). Users can change various source parameters in the loading map panel, such as burnup, enrichment, cooling, and assembly type, by clicking the respective fields. 


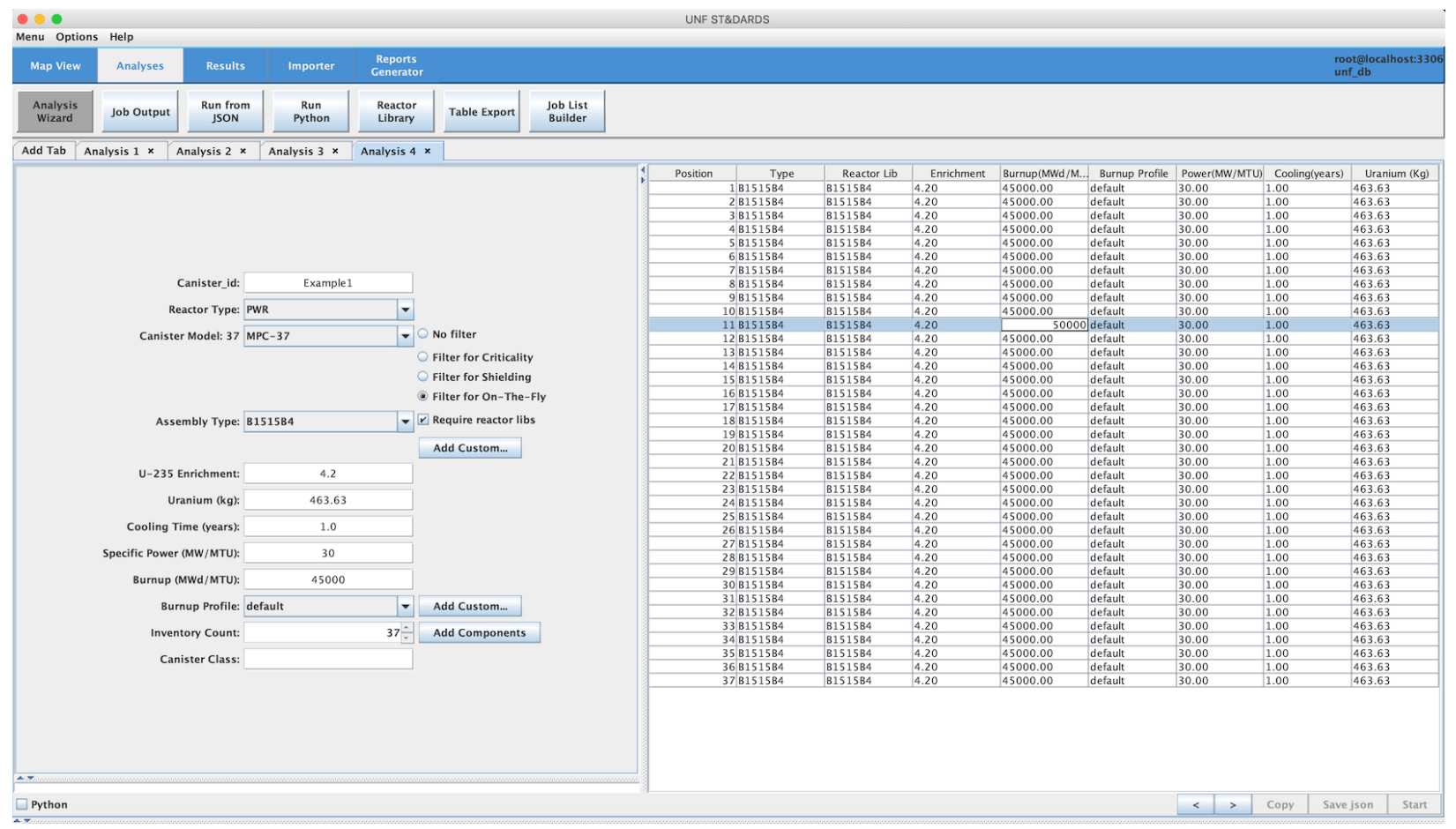

Figure 8: UNF-ST\&DARDS analysis wizard showing user-specified canister loading map.

On the next page/panel, users are directed to select options, including criticality, shielding, decay, and onthe-fly, as shown in Figure 9. On-the-fly is selected for this example. 


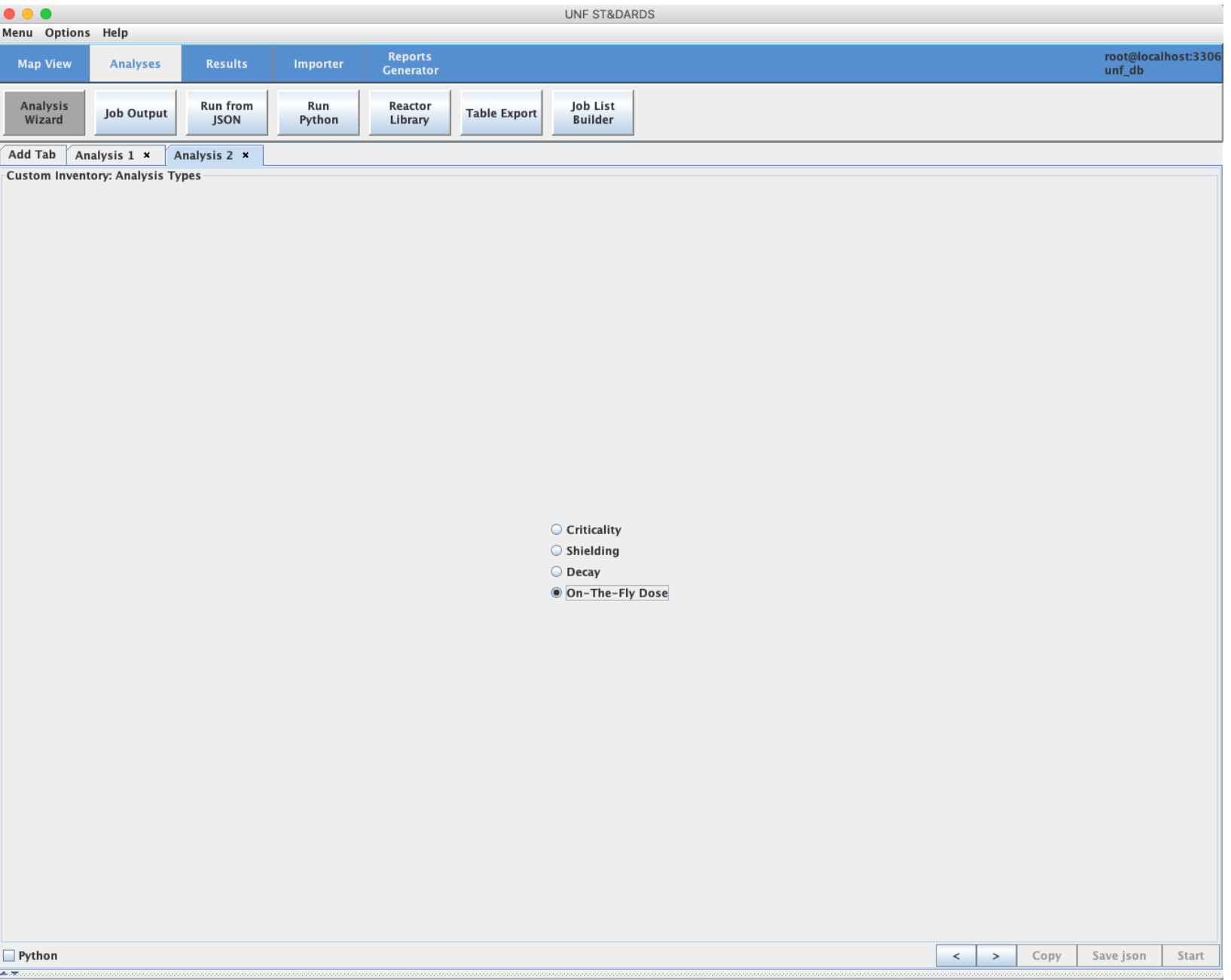

Figure 9: UNF-ST\&DARDS analysis wizard showing different analysis options for a canister.

On the next page/panel, users are directed to select analysis type (normal/accident) and overpack name as shown in Figure 10. Currently, only a normal analysis type with a HI-STORM FW overpack is available. Numbers of gamma and neutron energy groups are fixed and depend on the pre-generated on-the-fly libraries. User can view the groups used by clicking View Gamma Groups and View Neutron Groups at the lower left corner (Figure 10). Next, users can start the analysis by clicking the Start button located at the lower right corner (Figure 10). 


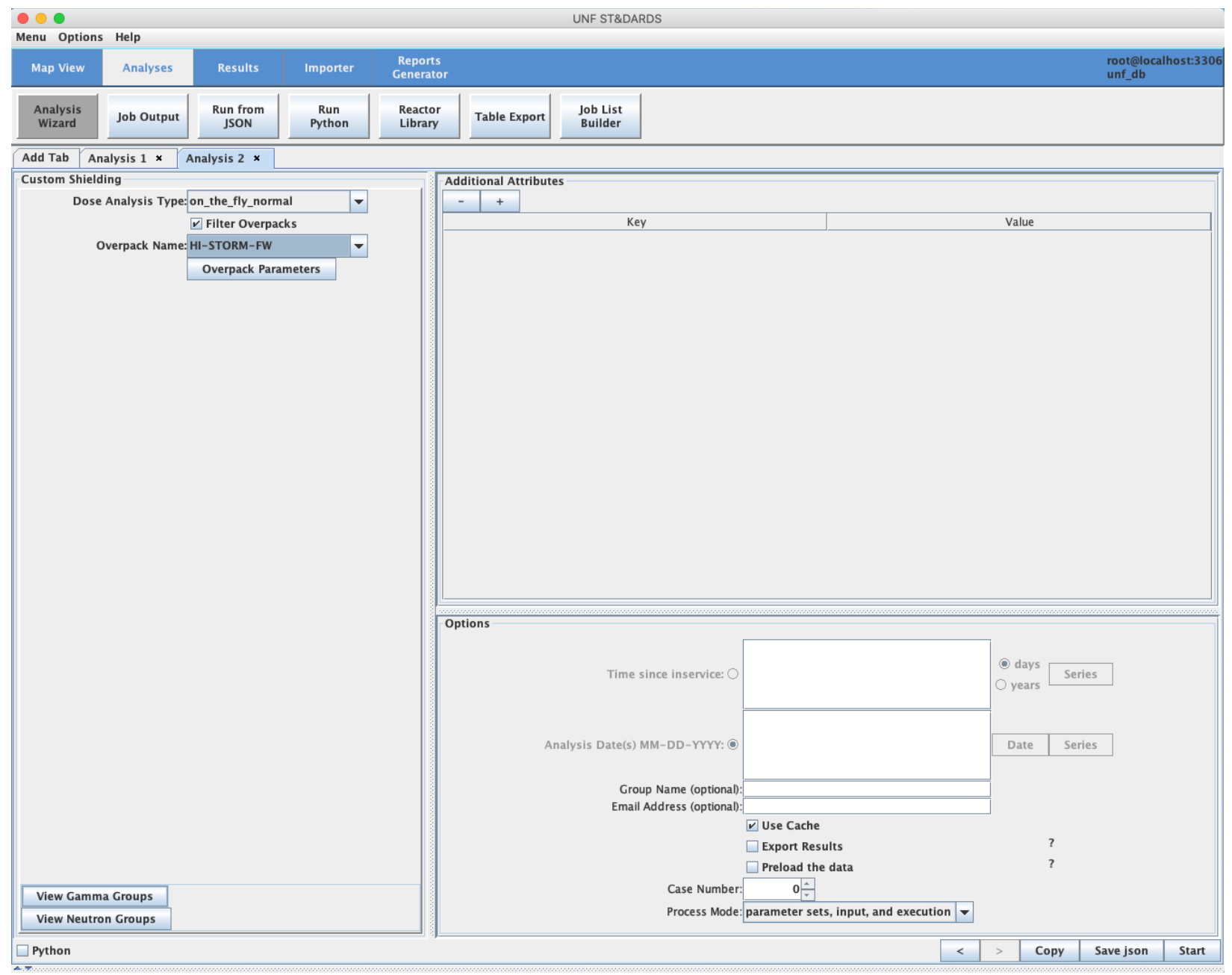

Figure 10: UNF-ST\&DARDS analysis wizard for executing an analysis.

Upon execution, UNF-ST\&DARDS opens the Job Output tab for tracking various analyses, as shown in Figure 11. UNF-ST\&DARDS will first perform the decay analysis and then run the Python on-the-fly dose calculator for calculating dose rates at various tally locations. If the job completes, UNFST\&DARDS provides a completion message at the bottom center of the page (Figure 11). 


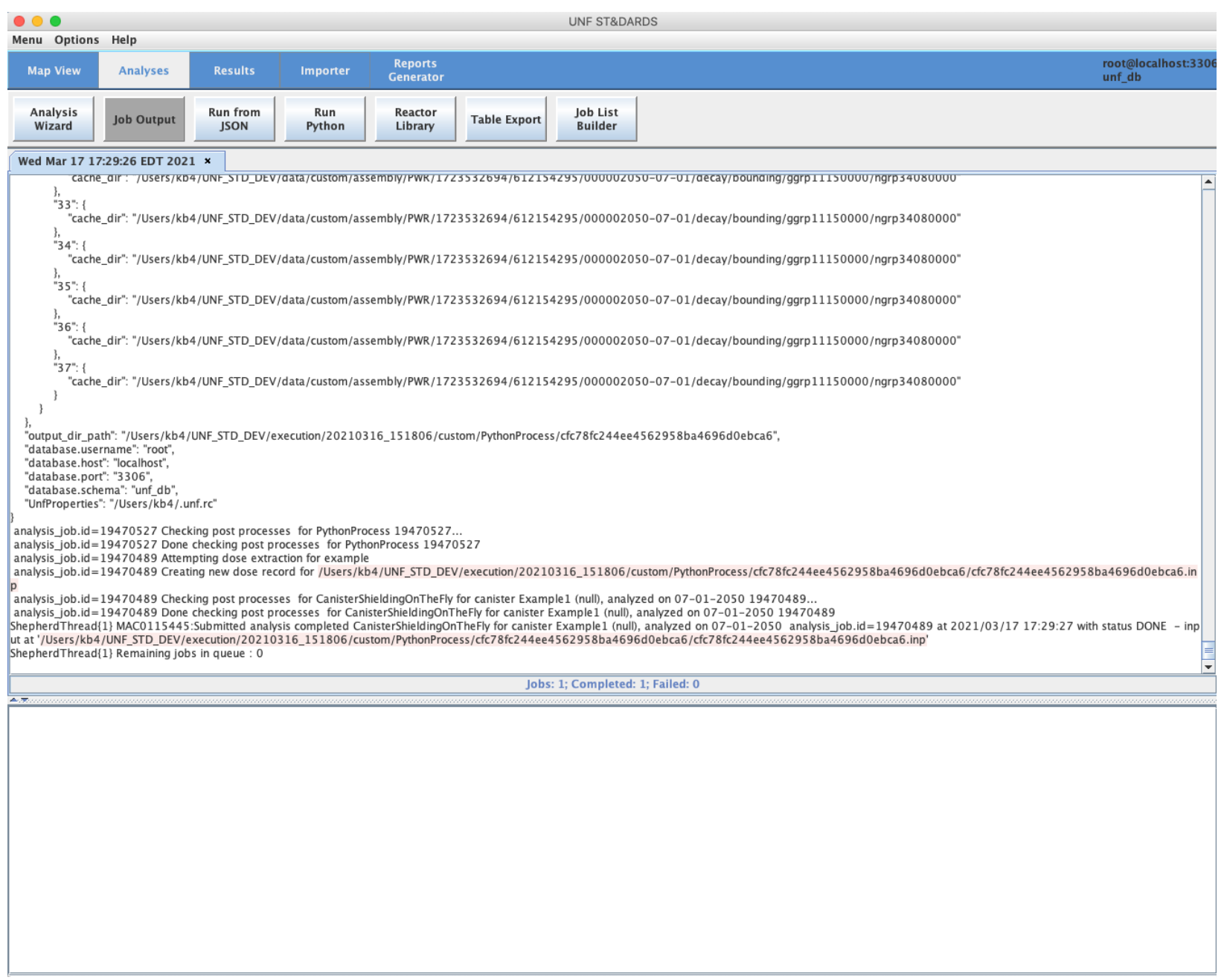

Figure 11: UNF-ST\&DARDS job output panel.

Users can check the results using Results $\rightarrow$ Custom Analysis $\rightarrow$ Shielding $\rightarrow$ Run as shown in Figure 12. Figure 12 shows example results (not based on real source calculations).

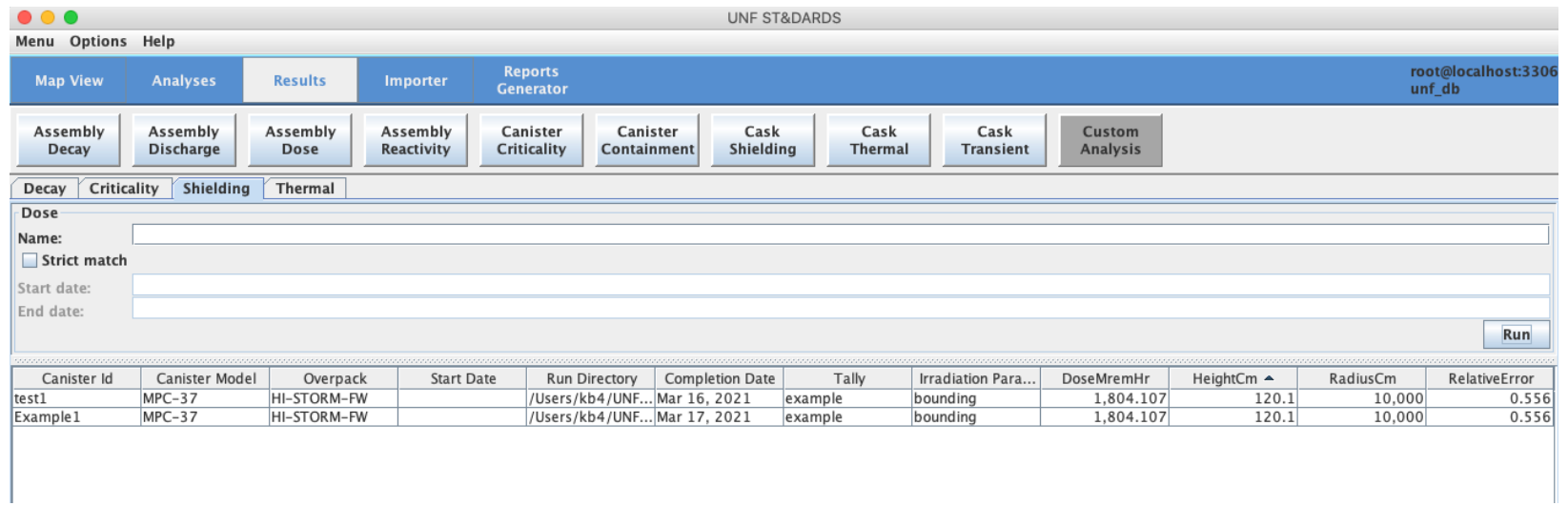

Figure 12: UNF-ST\&DARDS results browser. 


\section{CONCLUSIONS}

The on-the-fly shielding analysis method has been demonstrated as an alternative to the direct method for dose rate analyses of SNF transportation packages/storage casks. The direct method consists of Monte Carlo dose rate calculations with SCALE/MAVRIC simulating the actual as-loaded canister. The on-thefly method requires pre-generated dose rates by source particle type, energy group, and fuel geometry region for each transportation/storage system. To apply this method, radiation source regions and particle energy ranges are discretized into a reasonable number of spatial regions and energy groups. The pregenerated dose rates are independent of radiation sources associated with actual fuel assembly loadings. These dose rates become specific to the transportation package/storage cask after they are multiplied by the actual radiation source strength in each energy group and SNF spatial region, and the resulting dose rate values are summed for all energy groups and geometry regions. The results of the prerequisite Monte Carlo calculations are saved in a library and subsequently used to perform fast dose rate calculations using the SNF radiation sources for as-loaded canisters.

The on-the-fly shielding analysis method is demonstrated in this report for a HI-STORM FW storage cask containing 37 identical PWR SNF assemblies by comparison with reference dose rates. The dose rate values produced by the on-the-fly method were within the statistical uncertainties of the reference values. The demonstration was limited to dose rates produced by gamma and neutron radiation emitted from the active fuel region, which are main contributors to external dose rates. This report does not analyze gamma dose rates produced by activation sources in assembly hardware materials or secondary gamma radiation produced by neutron capture in fuel and structural materials. However, application of the on-the-fly shielding analysis method to these types of radiation sources is straightforward and will be implemented in future dose rate calculations.

The on-the-fly shielding analysis method was implemented in UNF-ST\&DARDS. A Python program was developed to process the MAVRIC dose rate results obtained by source particle type, energy group, and fuel geometry region. A Python processor created binary files, which were saved as a special UNFST\&DARDS library for on-the-fly shielding analyses. UNF-ST\&DARDS uses the precalculated on-thefly binary libraries generated by the Python data processor and directly executes the Python code for onthe-fly dose analysis. This Python code unzips the pregenerated binary files mentioned above, reads the data, and combines them with user-specified sources for dose rate and uncertainty calculations. The Python programs were verified using Excel calculations and by comparison with the values obtained with MAVRIC post-processing utilities applied to the $3 \mathrm{dmap}$ files. This method can currently be used to determine dose rates for as-loaded HI-STORM FW storage casks. The UNF-ST\&DARDS analysis wizard for on-the-fly shielding analysis was described in this report. The on-the-fly shielding analysis method eliminates the need for performing a Monte Carlo transport calculation using one processor for one to two days for each as-loaded configuration. The Monte Carlo simulation is replaced by a short radiation source term calculation and instant postprocessing calculations with the Python data processor. 
This page is intentionally left blank 


\section{REFERENCES}

1 J. M. Scaglione et al., "The Used Nuclear Fuel Storage, Transport, and Disposal Analysis Resource and Data System," Proceedings of Institute of Nuclear Materials Management (INMM) $-55^{\text {th }}$ Annual Meeting, July 20-24, 2014, Atlanta, Georgia (2014).

2. B. T. Rearden and M. A. Jessee, Eds., SCALE Code System, ORNL/TM-2005/39, Version 6.2.3, Oak Ridge National Laboratory, Available from Radiation Safety Information Computational Center as CCC-834 (2018).

3. G. G. Davidson and K. Banerjee, Toward On-the-Fly Dose Analysis Using the Shift Monte Carlo Code, Trans. Am. Nucl. Soc. 117(1), pp. 1178-1181, Oct 29 - Nov 2, 2017, Washington, D.C. (2017)

4. D. E. Peplow, "Monte Carlo Shielding Analysis Capabilities with MAVRIC," Nucl. Technol. 174 (2), pp. 289-313 (2011).

5. Final Safety Analysis Report on the HI-STORM FW MPC Storage System, Revision 4, Holtec Report No. HI-2114830, Holtec International (2015). 